\title{
The environmental aesthetics of Sarajevo: A city shaped by memory
}

This article discusses aesthetic singularity in present-day Sarajevo and shows how time generates a social response to the visual quality of space. Acknowledging the metamorphosis of the cityscape with regard to the identity reformulation of post-war Sarajevo, it examines the sensory engagement of people with the urban environment in relationship to the traumatic events and shifting realities imposed by globalisation. The hypothesis is that the environmental aesthetics of post-war cities are defined by the traumatic memory of physical and social destruction. This article offers insight within a broad range of theoretical discussions on the changes in the visual language and aesthetic quality of urban spaces in post-war Sarajevo.
In particular, it presents the notion of urban memory and its role in shaping the aesthetic experience in postwar cities. Finally, the findings show that architectural remnants, or ruins in the urban fabric, instead of being unstable entities, have the potential to become drivers of a continuum. Ultimately, this article accepts the values of incompleteness and opens new perspectives towards playful experimentation, which potentially relieves the aesthetic experience of a rigid and monotonous urban image.

Keywords: aesthetic experience, urban memory, visual language of a city, value of ruins, valued perception 


\section{Introduction}

In recent decades, many countries have experienced significant spatial transformations, leaving behind anomalies that remain deeply imprinted in the present-day city patterns. In parallel with often-mentioned urban changes, theoreticians proclaimed the development of smart cities (e.g., Castells \& Castells, 2010; Söderström et al., 2014; Wiig, 2015; Russo et al., 2016), launching an active discussion on how urban trends, global media and network societies are affecting city identity (e.g., Morley \& Robins, 1995; Parker, 2001; Hill, 2010; Kramer \& Short, 2011; Lopes de Souza, 2015). Inevitably, city identity is caught between the possibilities to create space for growth and the fact that globalisation results in many shifts, some of which are more culturally resonant than others.

These discussions on city identity become more complex when they are placed in the context of post-war cities. In addition, the superficial and often oversimplified understanding of identity politics, ethnic conflict and the reassertion of other cultures in the newly formed city constellation, as explained by Carl Grodach (2002), has been and continues to be either stereotypical or consumerist. Thus, today's heightened consciousness of identity raises many questions about urban authenticity that eventually pose a challenge to providing an adequate response to the identity crisis in post-war cities (e.g., Schwenkel, 2013; Kmezić et al., 2015; Pendlebury et al., 2015; Udelsmann Rodrigues \& Frias, 2016). In many instances, research into the ramifications of turbulent economic, political and social turmoil still does not sufficiently explain the notion of urban memory in the aesthetic experience of the places affected.

Sarajevo, the capital of Bosnia and Herzegovina, is an exemplary case of how globalisation under a specific social, economic and political regime can radically influence a once-strong cultural milieu. Known as the European city where East meets West with rich architectural heritage (Ottoman, Austro-Hungarian and Yugoslav), this city with an important administrative, political, cultural and economic status was subjected to significant changes in the aftermath of the 1992-95 war. Having been exposed to deep-rooted cleavages based on competing nationalisms and arguments over state legitimacy (Bollens, 2001), the cityscape suffered much lasting damage.

However, Sarajevo is not the only city affected by violent destruction in the network of the many capital cities in the western Balkans. From the Yugoslav wars of 1991-95 until today, distinctive urban transformations have occurred in many cities. These shifts left a permanent mark in the western Balkans, making it an experimental field for different approaches in crisis management. Moreover, to grasp the implications of this view, it is crucial to reconsider the specific features of Bosnia and Herzegovina and particularly of Sarajevo within the network of the post-war western Balkan cities.

Jasminka Udovički and James Ridgeway (2000) argue that the fate of Bosnia was a consequence of its location at the geopolitical and cultural heart of the former Yugoslavia. Among the six Yugoslav republics, Bosnia and Herzegovina was the most ethnically diverse (with Bosniaks, Croats and Serbs). As Edin Hajdarpasić (2015: 3) states, "Bosnia has become a global symbol of nationalist conflict and ethnic division in the twentieth and twenty-first centuries." During the war, in contrast to other western Balkan cities, Sarajevo underwent the longest siege of a capital city in the history of modern warfare, which lasted 1,359 days, from 2 May 1992 to 26 February 1996. Since the Dayton Peace Accord in 1995, Sarajevo has been divided by the Inter-Entity Boundary Line into two almost entirely mono-ethnic cities: Sarajevo in the Federation of Bosnia and Herzegovina and East Sarajevo, which is part of Republika Srpska. On one hand, the immense changes in Bosnia and Herzegovina brought the war to an end, but on the other hand they created fertile ground for further crippling of a war-torn nation.

All of this provides a reason to study the environmental aesthetic of Sarajevo as an exemplary case of a post-war city. Studying the identity of contemporary Sarajevo and looking back to the ethnic conflict may seem passé at first. The aim of this article is not to reopen old wounds or topics of "new wars" in post-conflict society, but to stress that the awareness of social, psychological and identity needs of diverse ethnic groups (Bollens, 2001) in the city lead to the city's reintegration and resilience.

This article discusses the aesthetic singularity in present-day Sarajevo and shows how time generates a social response to the visual quality of space. Accordingly, the hypothesis is that the environmental aesthetic of post-war cities is defined by the traumatic memory of physical and social destruction. The central questions of this article are: Has the visual language and aesthetic quality of urban spaces in post-war Sarajevo changed? What is the new visual identity of the multi-cultural and multireligious post-conflict society of Sarajevo? What is the role of urban memory and violent conflict in shaping aesthetic experience? What are the different perspectives on the urban perception and aesthetic values of architectural remnants or ruins?

The distinctive characteristics of post-war urban changes in Bosnia and Herzegovina and in Sarajevo are discussed in the first section of the article to provide a rationale for examining Sarajevo in the context of post-war cities in the western Balkans. In order to provide a conceptual framework for this 
article, the second section of the article explores the spatial relations that have emerged in Sarajevo, with an emphasis on the existing planning mechanism. To further understand the reconstruction and redevelopment of the city after violent destruction, attention is directed to the multiplicity of processes within the framework of the state apparatus. In doing so, the third section provides a theoretical background on the aesthetics of the urban environment, at the same time discussing different perspectives on urban perception and the aesthetic values of architectural remnants or ruins. The fourth section helps understand the notion of urban memory and its role in shaping the aesthetic experience in post-war cities. The fifth section draws analogies between this article and the crisis of city identity in the context of the western Balkans. Finally, the conclusion synthesises the findings and presents suggestions for future study.

In this examination of the identity of contemporary Sarajevo and the quest to discover alternative aesthetics, one of the main findings is that architectural remnants, or ruins in the urban fabric, instead of being unstable entities, have the potential to become drivers of a continuum. Ultimately, this article accepts the values of incompleteness in the environment and opens a new perspective towards playful experimentation, which potentially relieves the aesthetic experience of a rigid and monotonous urban image.

\section{The crisis of Sarajevo's urban identity: a last call for rescue}

Contemporary architecture in Sarajevo defies time and consciously creates urban agitation, thereby disrupting the formerly unique visual identity of well-known architectural tradition. The violent destruction that occurred during the latest war created a temporal and developmental vacuum, resulting in the inability of contemporary social and architectural aspirations and trends to create any kind of symbiosis with the pre-existing urban context. Therefore, one of the most frequent discussions in Sarajevo's transitional period has been about the post-war development that revolves around a series of social, political and economic issues (e.g., Karahasan \& Drakulić, 1994; Morley \& Robins, 1995; Bollens, 2001; Perry, 2003; Donia, 2006; Sorabji, 2006; Bougarel et al., 2007; Markowitz, 2007; Pilav, 2012; Gül \& Dee, 2015).

In many instances, the post-war development of Sarajevo was a consequence of diverse international, local and political influences, resulting in a complex web of bureaucratic hierarchy. Nowadays, a major difficulty is the complexity of bureaucratic hierarchy and stagnancy of the legal framework, which cannot support rationalised strategic decisions for further urban

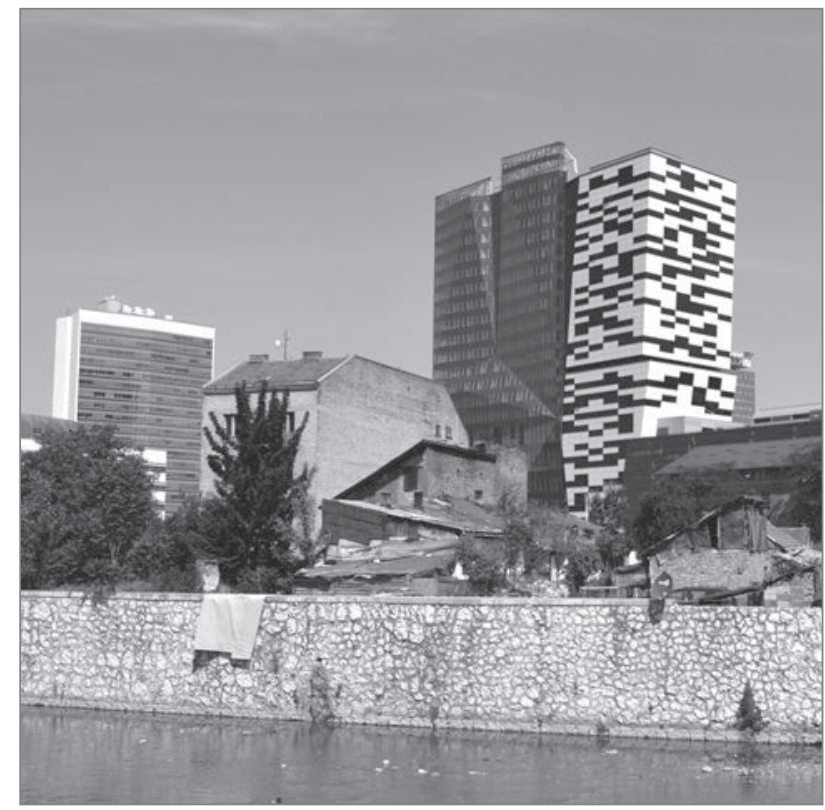

Figure 1: Contemporary architecture in Sarajevo (photo: Erna Husukić).

development. Subsequently, the overarching present outcome is an urban environment that is unable to facilitate human interaction with space.

The counterproductive urban land policy is a hotbed of spatial errors, which further negatively impacts urban development. To some extent, this may be because the planning system itself is inflexible in its response to market pressures, which makes it impossible to understand, control and predict urban growth. As such, the existing planning system continues to sustain profound and unprecedented spatial changes. Therefore, relying on the existing planning system without a well-prepared institutional infrastructure means that is not possible to create a stable, countrywide planning approach (Husukic, 2015).

Subsequent spatial configuration lacks organisation and planning in the generic sense, and also lacks sensitivity toward the local culture. The urban transformation in post-war Sarajevo has resulted in immense challenges regarding aesthetic reality. A valuable but significantly fragmented cityscape is aesthetically highly sensitive to interventions forced upon it by imposed global architectural trends, raising questions of aesthetic insensitivity and endangering the city's visual identity.

The newly established haphazard patterns of development distort the urban image of Sarajevo and create a negative projection on the city identity. The invasion of new and formless spaces demolishes all elements of emotional safety with the riddle of space produced by the inconsistencies of spatial form. The silhouette of twenty-first-century Sarajevo (Figure 1) is 
nothing more than the sum of vertical congestions that has completely altered the cultural landscape.

These approaches to space are creating a continual dissolution of Sarajevo's urban form. As such, the wildness of construction and tiredness of urban space, as well as the fuzziness of in-between zones, are creating an emptiness in mental maps. Thus, an aesthetically positive experience is questionable because today's urban image is abruptly severed by full disregard for the city layers.

From the discussions on Sarajevo's urban identity to date, it is noticeable that the result of such harsh design is a monotonous environment that can hardly be grasped by common traits in perception, and in which a once-present sense of unity has disappeared. The loss of unity and the sense of visual order could cause an absence of the essence of aesthetic experience and even sanity (Dewey, 1995). Within this perspective, Erik Erikson (1993) claims that the sense of unity for both an individual and a member of a group is an important counterpoint for psychological growth and health.

In addition to the aforementioned negative aspirations of the globalised world to impose false glitter on a city, as mentioned by Monica Montserra Degen and Gillian Rose (2012), it must be highlighted that the contemporary environment is much more than a stylised urban space that will eventually be experienced through multiple sensory modalities. Such tendencies underline the importance of the sensorial qualities of space, confirming that the simplification of the contemporary urban image results in insensitive spaces to any perceptual stimulation (Nohl, 2001).

Anticipating the consequences of contemporary interventions in Sarajevo, which are also reflected in the anaesthetic state of the urban environment, the city faces the risk of a visual deficit. In addition, in this anaesthetic state, the landscape has lost its narrative as well as its poetic aspects (Nohl, 2001). However, there is a widespread belief that the search for a stable identity inevitably involves nonlinear and complex problems (e.g., Geyer \& Rihani, 2010; Innes \& Booher, 2010) because it is affected by multiple and shifting realities of the contemporary world.

In contrast to aestheticised architecture, the pursuit of unique aesthetic qualities and a meaningful environment in Sarajevo could actually lead to a quest for spaces that are not subordinated to the power of the contemporary world. In that context, architectural remnants or ruins are recognised as a possible catalyst for creating an urban image, with the potential for reflecting positive aesthetic elements of Sarajevo. Although such ruins do not possess a harmonious pattern that can be found in traditionally conceived "beautiful" environments, their aesthetic values could be traced along their mysterious nature. In line with the claims of Werner $\operatorname{Nohl}(1995$, cited in Nohl, 2001), "today's aesthetic fascination lies very often in the self-dynamics, in the self-productivity and the self-regulation power of nature".

At the same time, in the monotonous and intermittent chain of spatial relations, ruins could be seen as fertile ground for aesthetic intensifications. Under the assumption that the state of ruination is temporary, ruinous environments can represent a smooth perceptual transition between extensive aesthetic values of traditional parts of Sarajevo, and imposed aesthetic values of contemporary formations within the cityscape.

\section{The aesthetic value of architectural remnants or ruins}

The way in which one understands aesthetics has ensured various interpretations of the urban environment. For some, the quality of space is defined by beauty and a certain logic of formal and visual elements in the environment. In addition, cognitive factors rely on the legibility of space, making identity, perceptibility and mental maps factors that influence aesthetic values. In his discussion on the fundamental concepts of the new aesthetics, Gernot Böhme (1993: 125) stated that "aesthetics represents a real social power. There are aesthetic needs and an aesthetic supply. There is aesthetic manipulation. To the aesthetics of the work of art we can now add with equal right the aesthetics of everyday life, the aesthetics of commodities and a political aesthetics. General aesthetics has the task of making this broad range of aesthetic reality transparent and articulatable."

Furthermore, it must be understood that the architectural atmosphere acts as a sensual and aesthetically enfolding concept of the built environment. Looking at the environment as a semiotic transfer picture of society, dynamism in the city development must be accepted, in which material built culture is "a part of on-going (re) design of the world" (Jacobs \& Merriman, 2011: 217).

Prior to discussing the aesthetic values of architectural remnants or ruins, one must be acquainted with the different perspectives of urban perception. This article relies on three dominant types of urban perception: operational, responsive and inferential (Appleyard, 1973). Operational perception is directed by purposeful actions and is determined by particular and functional aspects of the environment. Responsive perception, on the other hand, is conditioned by the physical environment and leads to more passive relations between the 
observer and the environment. Finally, inferential perception as probabilistic in nature tends to form a recognisable system and codes as based on past experience.

Positioning the urban perception of ruins in the context of post-war Sarajevo, and observing ruins as objects that have lost their primary function due to violent destruction, attractiveness is based on disorder and "ugliness", but most of all the viewer's emotional reaction. In this sense, inferential perception is imposed as the rational criterion in the analysis of the totality of the perception of architectural remnants. Such an evaluation of aesthetic quality is defined by Arnold Berleant (2002) in "Notes for cultural aesthetics" as valued perception, or as a consequence of processing perceived visual information through a system of previously obtained knowledge and experiences finally forming an opinion on aesthetic quality.

Put into a wider context, regardless of the cause of the object's ruinous state, the peculiar status of ruins is generally understood through negative connotations. This mode of thinking about ruins results in an often conflicting attitude, in which ruins are seen as an "ambiguous and controversial phenomenon within current discourse and practices" (Olsen \& Póra Pétursdóttir, 2014: 4). However, although it is an aesthetic and conceptual category, a ruin is uniquely ill-defined (Hell \& Schönle, 2010). Its vulnerability is compounded by its disreputable status, although according to Hanna Katharina Göbel (2015) ruins are actively included in the makings and unmakings of the socialities "inside" and "outside".

Furthermore, different aesthetic values are derived from Albert Speer and Walter Benjamin's conceptions of ruination. For Speer, a ruin provides an established conduit for aesthetic effect, a means of adding or accumulating "age value", not in pursuit of historical truth, but rather a mythological history as supported and authorised by the ruin's picturesque aesthetic (Stead, 2003). Hence, for Speer the process of ruination is entirely aesthetic, and it represents not a reduction but an accretion of myth. Conversely, Benjamin claims that ruination can be construed as the means of laying bare those truths buried under layers of false romantic aesthetics (Stead, 2003). Thus, the most recognisable aesthetic value of remnants presented in the work of Adorno, Benjamin, and so on is the value of the fragment. It is the incompleteness or character of "halfbuilding, half-nature" as driven by incidental or accidental appearance, indicating the fragmented nature of land; the appreciation of natural and manmade process leads to the ingenuous beauty present in fragmented nature. However, the visual impression of ruins varies in response to the specific context.
The discussion in this article is not only oriented towards the standard preoccupations within aesthetics, such as visual language, but also relies on Theodor Adorno's Aesthetic theory (1970) and the relations between art and society. Moreover, through the lens of Paul Zucker (1961), ruins are hybrids in which he sees the ambiguous emotional impact that is aesthetically neither in the realm of art nor in the realm of nature.

In the case of Sarajevo, city ruins are evaluated beyond their aesthetic values, essentially as artefacts of the traumatic past. In assessing the aesthetic significance of ruins, this article searched for recognisable links between urban experience and the personal and transmitted memories introduced by Cornelia Sorabji (2006). Following Sorabji's (2006: 2) article on urban memory, one may see "that everyone who experiences war is lastingly, psychologically deformed and that the deformity can be xeroxed down the generations by the simple means of repeating stories of suffering to one's children."

Through narratives or through silent landscapes of past remnants, residents experience a new dimension of space relying on their own senses; spontaneous vegetation permits humans to interact with measures of senses, responses and impulses. Furthermore, ruins could become successful ventures towards the creation of a consistent and visually pleasurable urban image. Even though a ruinous setting is not strategically planned to illuminate the emotional dimensions of aesthetic experience, at this point it is significant to acknowledge the perception of ruins as a cognitive process under specific circumstances.

Nevertheless, despite an undeniable impact of traumatic events, this article may help rethink the status of Bosnia in a way different from its widely acknowledged label as a land "deeply divided and steeped for generations in tales of heroism and imbued with a quasi-religious ethos of revenge and retribution" (Simic, 2000: 115).

\section{Urban memory shaping aesthetic experience}

"Urban memory can be an anthropomorphism (the city having a memory) but more commonly it indicates the city as a physical landscape and collection of objects and practices that enable recollections of the past and that embody the past through traces of the city's sequential building and rebuilding" (Crinson, 2005: xii).

The contemporary urban environment of Sarajevo is a shattered collage of cultural and aesthetic experiences. The evergrowing consumption of land (see Figure 2) disrupts the city's urban pattern, seemingly turning the new development in a 


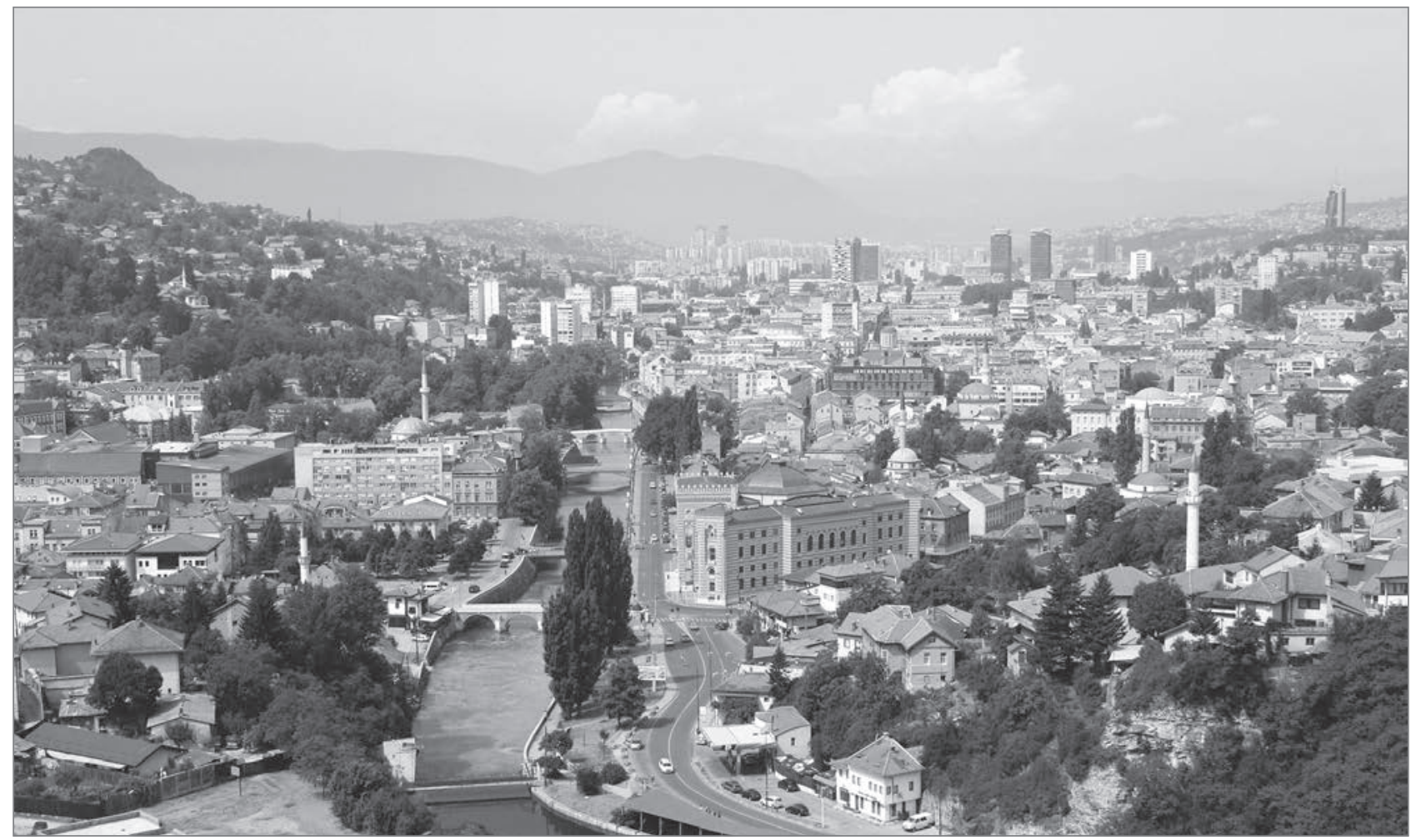

Figure 2: Multi-layered cityscape of Sarajevo (photo: Julian Nitzsche).

totally opposite direction. The formerly unwritten laws of Sarajevo (Grabrijan et al., 1957), with its cultural inheritance, ethical principles and indigenous ideas, have been reduced and dangerously altered.

In dealing with the coherence of the urban context, and the overwhelming social, political and economic connotations, the city faces the difficulty of identifying clear aesthetic features. In the case of Sarajevo, every phase of city development is perceived and experienced primarily through a symbolic character rather than defined through actual aesthetic qualities. Strict categorisation is evident between what is perceived as a "beautiful environment" (the historical core of the city, dating from the Ottoman and Austro-Hungarian period, is traditionally considered "beautiful"), a "prosperous environment" (zones within city that undergo strong redevelopment mostly through foreign financial assistance; Gül \& Dee, 2015) and an "ugly environment" (neglected land or buildings in a ruined state).

In Sarajevo, ruins bring to mind wartime destruction (see Figure 3) instead of natural decay. The widespread destruction "leaves scars on the human unconscious which are the source of our most enduring and profound memories" (Crinson, 2005: 5). More importantly, the planned obliteration of one ethnic group led to the social estrangement, spatial fragmentation and the general state of confusion. It is evident, in the case of Sarajevo, that the "possibility of knowing traumatic

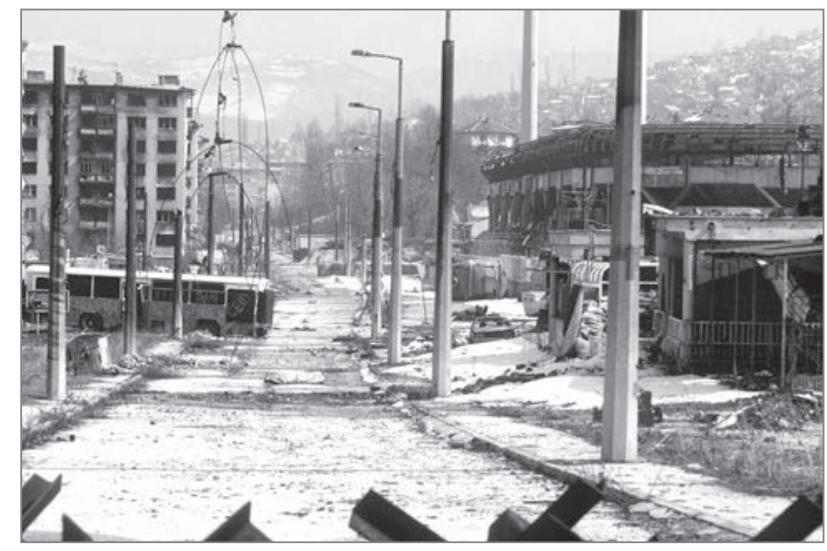

Figure 3: Sarajevo at the end of war (photo: Stacey Wyzkowski).

history becomes a function of future recognition" (Crinson, 2005: 15). Indeed, identifying the cause or action triggering the ruination produces a strong determination for the beautification of the environment.

In the twenty-first century, the cityscape is full of residues (see Figure 4) that are generated by collective trauma, and so the presence of ruins is seen as an initiator of difficult memories. For the city's residents, ruins are eerily reminiscent of traumatic events and are understood as interruptions that disturb and evoke memories of disaster and loss. Certainly, the pernicious condition of space is subordinated to the predominant collective painful memory. 


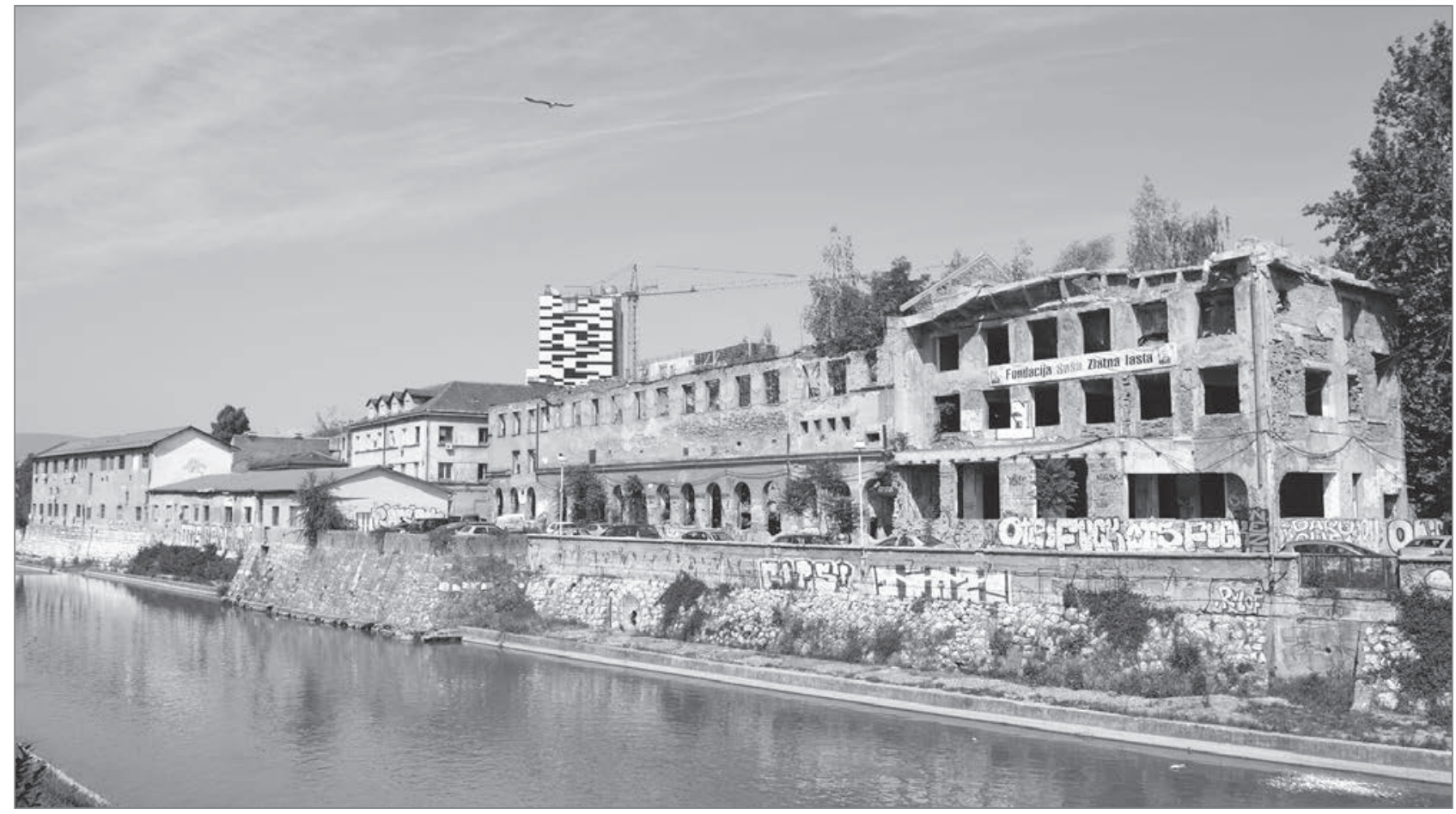

Figure 4: Ruins of Sarajevo (photo: Erna Husukić).

Thus, it is only natural that the strong negative historical connotations associated with ruins greatly impact and even determine Sarajevo residents' perception and related visual experience. In the case of Sarajevo's ruins, a negative feature can override the positive and become the crucial element in determining aesthetic values. As already mentioned, once a negative perception is created, there is a serious risk of it being transferred across generations.

In this context, Valery Perry (2003: 16) discusses how war affects people's perceptions and worldviews, emphasising that "reframed opinions are then transmitted from adults to children, either informally at home or formally in the schools." This is clearly the case in Sarajevo and elsewhere in Bosnia and Herzegovina, where the histories of centuries past are seen as key determinants of recent urban perception. As Sorabji (2006: 1) states, "the personally meaningful images and ideas of younger generations who did not experience the war but who have lived in intimate contact with elders who did, are also helping, in some less direct way, to shape attitudes towards the social and political environment."

The traumatic memory of physical and social destruction is an omnipresent post-war trace that allows Sarajevo to embark upon the path of newly justified spatial relations. In other words, ruins, or their evaluation through perception, are identified as the dysfunctional elements in the urban memory of Sarajevo that evoke a positive aesthetic experience. Therefore, to understand the current drawbacks in the urban develop- ment and planning system of Sarajevo, the complex relations between the visual manifestation of architectural legacy, ruins and various psychological attitudes (Zucker, 1961) must be taken into consideration. After defining the major issues of today's urban perception of the Sarajevo cityscape, the urgency and the need for exploration of new alternatives is recognised, which could potentially arise from the multi-layered city environment.

In this sense, this article supports the positive aspirations illustrated in the article "Managing memories in post-war Sarajevo: Individuals, bad memories, and new wars" by Sorabji (2006), which puts aside negative consequences of traumatic events, shifting the focus from memories and political dynamics that control individuals to the importance of "the individual's awareness of memory and his or her desire to control it for the perceived benefit of self and others" (Sorabji, 2006: 3). Accordingly, this article argues that an individual's awareness of memory also suggests a way of thinking about the prosperous future in terms of how to embrace new possibilities among fragmented systems. In the end, what matters the most is the ability to cultivate awareness and thus to create greater capacity to acknowledge diversity.

This section showed that the evaluation of aesthetic quality, in the case of Sarajevo, lies between the visual experience of physical form and traumatic events. Hoping to discover an alternative aesthetic, the ruins are recognised not only as an 
indispensable part of the urban landscape and ambient, but also as an important factor in forming the overall local culture and society. In a paradoxically simplified environment of contemporary additions, the aesthetic experience of ruins is seen as an exciting possibility for new visual expression, or a catalyst of positive development. The disputed visual deficit evident across all cycles of spatial development in Sarajevo could be diminished by the involvement of ruins in the creation of new identity. In pursuit of spatial dignity and the emotional sensitiveness of emerging aesthetics, the visual properties of ruins transcend the aesthetic values of a profit-oriented environment. In order to do this, one must come to understand the evasive nature of ruins and take a leap into the unknown, leaving behind traumatic memories.

\section{Discussion}

From assessing the post-war development in the western Balkans, it is evident that each country has moved forward at a different pace. Many studies have been conducted on the post-war situation and future endeavours of Serbia, Croatia, Slovenia, Bosnia and Herzegovina, Kosovo, Macedonia and Montenegro (e.g., Benderly \& Kraft, 1996; Thomas, 1998; Sell, 2003; Schuman, 2004; Thomas et al., 2006; Clark, 2008). However, there has not been a broader discussion on how the dissolution of Yugoslavia and balkanisation affect the identities of western Balkan cities and, in particular, the national capitals (Belgrade, Zagreb, Ljubljana, Sarajevo, Prishtina, Skopje, and Podgorica).

One might argue that warfare, despite its negative consequences, also creates various opportunities for cities to be redeveloped and to seek out new identity. However, the cityscape of the national capital cities in the western Balkans that displays generations of buildings is filled with contemporary architectural creations today that can be observed only as anti-cultural enclaves. This is because the reconstruction of the western Balkan cities following the 1991-95 war was nothing more than an urgent reaction to the emerging situation. It is not difficult to understand why. Recovery had to be carried out quickly and it was spawned by the necessity to clear rubble away and provide basic housing and infrastructure. Judging from various examples of the post-war cities in the western Balkans, the lack of thought-out interventions left little if any room for conscious and planned reshaping of the urban environment.

At the same time, post-war cities are subject to the impact of foreign investors and political authorities more than other cities. Therefore, under the patronage of powerful authorities, cities become "victims" of market forces, rather than the result of systematic urban planning based on the long-term civic context. In many instances, purely financial involvement in the shaping of post-war city identity resulted in aesthetic sterility.
In the context of the former Yugoslavia, the roots of the new identity of post-war cities might be traced back to even before the Yugoslav wars. In particular, this article refers to the arguments of Maroje Mrduljaš and Vladimir Kulić (2012) on architectural and urban planning practices in the former $\mathrm{Yu}$ goslavia and the project "Unfinished modernisations: Between utopia and pragmatism," in which they claim that in today's physiognomy of the built environment it is possible to detect partially articulated and unfinished modernisations (Mrduljaš et al., 2012). This leads to the conclusion that the new visual identity of western Balkan cities is the outgrowth of an unfinished context, which might be seen as a result of unfinished modernisation and balkanisation.

In addition, Rolf Sternberg (1991) argues that history and culture are the most important factors affecting the course in which aesthetics are included in the evolving urban fabric. In essence, drawing on the diverse history and culture of the national capitals, there has been a radical shift to the architectural and urban vision as explained and discussed by Srdjan Jovanović Weiss (2013). In stark contrast to other post-war cities in the western Balkans, "Sarajevo with its European and American-led renovations, has become largely forgotten, a town hurt by extensive "brain drain" and now sinking into apathy" (Jovanović Weiss, 2013: 103). Such a result and perception of Sarajevo was probably inevitable because the city has become a casualty of its unfortunate fate, in which its physical division can be understood as the leftover, the legacy and ultimately the symbol of the seemingly indelible ethnic differences of Yugoslavia.

In Sarajevo there have been persistent activities that have continuously denied the city identity. Even with many attempts to stabilise city development after the war, the issue of legislation was never adequately addressed, in which many omissions in the existing planning mechanism further endorse the manipulation of spatial consumption. At the same time, the views of local authorities on city development are influenced by political and financial power, whereby unexpected amendments to existing urban plans are adopted. Specifically, outdated plans, spatial manipulation, questionable decision-making processes, fuzzy ownership issues, proliferation of illegal buildings and a lack of systematic planning have caused numerous spatial patchworks in the Sarajevo cityscape.

It is apparent that the system of values in Sarajevo is multi-layered and is the result of an attempt at cultural evolution. Thus, the crisis of Sarajevo's identity is not the result of a missing national identity in Bosnia because Bosnia, more than other countries in the Balkan region, has long been considered a quintessential example of transculturation (Todorova, 1997). Rather, the crisis of Sarajevo identity is the result of the in- 
ability of local culture to evolve and adjust to the change of social and political order that is further enhanced by power struggles of various post-war elites involved in city planning and development. The post-war local identity of Sarajevo is reinterpreted through international conceptions of the city and its history and through economic motivations. Following the claims by Grodach (2002), identity has probably never been hermetically constructed, but emerges from an intersection of global and local influence. For him, the roots of Bosnia's hybrid cultures can be traced to a long history of coexistence of three distinct ethnic groups.

Despite endeavours to overcome traumatic urban memories through city reconstruction, redevelopment and reconciliation, there is still a multitude of concerns and issues that hamper future development of this region, such as "lasting tensions caused by ethno-political and/or territorial issues; differently perceived "truths" regarding the previous wars by regional actors; half-assed reforms conducted in political environments with partly continuing criminal networks still representing huge challenges in the process of conflict transformation" (Felberbauer \& Landesverteidigungsakademie, 2010: 5). Indeed, two decades later, there is still much talk about self-renewal and what cities should look like.

Whether talking about Ljubljana, Zagreb, Belgrade, Sarajevo, Skopje, Podgorica, or Prishtina, apart from spatial relations, city leaders and policymakers must also understand the complex social-psychological and identity needs of diverse ethnic groups within the urban region (Bollens, 2001). More importantly, unless and until the city authorities become aware of the consequences of superficial decisions and profit-oriented urban development, an antisocial environment will prevail in the cityscape of cities. Without a national planning agenda and concern for the long-term prosperity of society, the already fragile environment of post-war cities will be further weakened.

\section{Conclusion}

"That's why we sail. So our children can grow up and be proud of whom they are. We are healing our souls by reconnecting to our ancestors. As we voyage we are creating new stories within the tradition of the old stories, we are literally creating a new culture out of the old" (Nainoa Thompson, cited in Davis, 2009: 35).

While focusing on the analysis of the environmental aesthetic of post-war Sarajevo, this article explores the sensibility of a multi-ethnic nation that rests on the physical boundaries created by the Dayton Peace Agreement of 1995. The approach employed in this article suits Sarajevo within a wider research context, and it opens up great possibilities for researchers to widen their perspective on various aspects of post-war development.

Sarajevo's search for identity has never been greater as it struggles to overcome subaltern histories and to adapt to rapidly changing circumstances. However, the city is growing under constant pressure and requires an openness to multiple perspectives. This work has identified the need for more responsive, fluid development that will support spatial and social transformation. The visual response and identity crisis of Sarajevo must currently be observed from the perspective of the decomposition and reconstitution of the city within its own boundaries.

In many instances, the aesthetic reality of Sarajevo says more about the political, economic and social regime of the nation then it does about the aesthetic values of the space itself. The past remnants are based on particular laws in which imaginary wholeness is reflected through the endurance of the past. Thus, this article argues that, as the result of transformation that the space endured during the past two decades, the urban experiences will inevitably lead to an alternative aesthetic.

Therefore, this article confirms the initial claim that the environmental aesthetic of post-war cities is defined by the traumatic memory of physical and social destruction. However, as this article shows, the aesthetics are also influenced by the malformations of traumatic memory that took place during these past twenty years, leaving very few possibilities for a positive solution.

In that context, ruins, the "reminders" of devastation - are the buildings that are singled out to have the potential to be the initiators of positive change. It must be emphasised that they are not of national, political or social importance, but they are still present as striking and daunting artefacts. This means that the exclusion of urban memory from the aesthetic experience is not promoted, but nonetheless this work claims and encourages the creation of a reasonable system of values, which could overcome negative spatial connotations and include ruins as equal actors in the formation of the overall image of Sarajevo. Therefore, by promoting the aesthetic qualities of ruins, the initiation of changing perspectives of post-conflict society is suggested. This article recommends their appropriate integration into the urban fabric, which can potentially be a trigger for healing the collective wounds.

This article argues that ruins can be seen as unintentional monuments, with the value of fragments, but also are fertile ground for a humble beginning of new development. As noted earlier, it does not force the retention of the visual form of ruins, but 
merely recognises their presence and strong allure as fragments. Furthermore, the specific character of visual language can be used as a basis for the creation of new spatial values.

It has been shown that the search for the vanished identity of Sarajevo could be the search for sensory experiences that, according to John Brinckerhoff Jackson (1980), are the most reliable sources of self-knowledge. Moreover, in the effort to understand the subsequent spatial order, priority should be given to rethinking attributes of the cityscape and observing ruins as milestones that could enrich the aesthetic imagination and create "a new culture out of the old."

Although the topic under review offers valuable insights into the dynamic relationships among the main actors involved in the development of post-war Sarajevo, in order to improve the understanding of the consequences of the altered urban aesthetic, this work calls for further research. In this regard, the findings establish avenues for additional studies on the nexus between the environmental aesthetic of post-war cities and the quality of life.

\section{Erna Husukić}

International Burch University, Faculty of Engineering and Informa-

tion Technologies, Department of Architecture, Sarajevo, Bosnia and Herzegovina

E-mail: erna.husukic@gmail.com

Emina Zejnilović

International Burch University, Faculty of Engineering and Informa-

tion Technologies, Department of Architecture, Sarajevo, Bosnia and Herzegovina

E-mail:emina.zejnilovic@gmail.com

\section{References}

Adorno, T. W. (1970) Ästhetische Theorie. Frankfurt am Main, Suhrkamp Verlag.

Appleyard, D. (1973) Notes on urban perception and knowledge. In: Downs, R. M. \& Stea, D. (eds.) Image and environment: Cognitive mapping and spatial behaviour. Chicago, Aldine Publishing Company.

Benderly, J. \& Kraft, E. (1996) Independent Slovenia: Origins, movements, prospects. New York, St. Martin's Press.

Berleant, A. (2002) Notes for a cultural aesthetic. Koht ja Paik / Place and Location, 2, pp. 19-26.

Böhme, G. (1993) Atmosphere as the fundamental concept of a new aesthetics. Thesis Eleven, 36(1), pp. 113-126. DOI: $10.1177 / 072551369303600107$

Bollens, S. A. (2001) City and soul: Sarajevo, Johannesburg, Jerusalem, Nicosia. City, 5(2), pp. 169-187. DOI: 10.1080/13604810120092454

Bougarel, X., Helms, E. \& Duijzings, G. (eds.) (2007) The new Bosnian mosaic: identities, memories and moral claims in a post-war society. Aldershot, Ashgate.
Castells, M. \& Castells, M. (2010) The rise of the network society. Malden, Wiley-Blackwell.

Clark, J. N. (2008) Serbia in the shadow of Milošević: the legacy of conflict in the Balkans. London, Tauris Academic Studies.

Crinson, M. (ed.) (2005) Urban memory: History and amnesia in the modern city. New York, Routledge.

Davis, W. (2009) The wayfinders: Why ancient wisdom matters in the modern world. Toronto, House of Anansi Press.

Degen, M. M. \& Rose, G. (2012) The sensory experiencing of urban design: The role of walking and perceptual memory. Urban Studies, 49(15), pp. 3271-3287. DOI: $10.1177 / 0042098012440463$

Dewey, J. (1995) Art as experience. New York, Berkley.

Donia, R. J. (2006) Sarajevo: A biography. Ann Arbor, University of Michigan Press. DOI: 10.3998/mpub.189593

Erikson, E. H. (1993) Childhood and society. New York, Norton.

Felberbauer, E. M. \& Landesverteidigungsakademie (eds.) (2010) 15 years of peace-building in the Western Balkans - lessons learnt and current challenges. Vienna, National Defence Academy.

Geyer, R. \& Rihani, S. (2010) Complexity and public policy: A new approach to twenty-first century politics, policy and society. London, Routledge.

Göbel, H. K. (2015) The re-use of urban ruins: Atmospheric inquiries of the city. New York, Routledge.

Grabrijan, D., Neidhardt, J., Moll, P. \& Vrčon, B. (1957) Architecture of Bosnia and the way modernity [sic]. Ljubljana, Državna založba Slovenije.

Grodach, C. (2002) Reconstituting identity and history in post-war Mostar, Bosnia-Herzegovina. City, 6(1), pp. 61-82. DOI: 10.1080/13604810220142844

Gül, M. \& Dee, J. (2015) Sarajevo - A city profile. Cities, 43, pp. 152-166. DOI: 10.1016/j.cities.2014.11.018

Hajdarpasić, E. (2015) Whose Bosnia? Nationalism and political imagination in the Balkans, 1840-1914. Ithaca, Cornell University Press. DOI: 10.7591/cornell/9780801453717.001.0001

Hell, J. \& Schönle, A. (eds.) (2010) Ruins of modernity. Durham, Duke University Press.

Hill, D. (2010) Unstable identities in the networked city. City, 14(1), pp. 199-202. DOI: 10.1080/13604810903538051

Husukic, E. (2015) Terrain vague in Sarajevo. In: ARCHDESIGN '15: Current trends and methodologies on architectural design; Architectural Design Conference Proceedings, pp. 561-571. Istanbul, Dakam Yayınları.

Innes, J. E. \& Booher, D. E. (2010) Planning with complexity: An introduction to collaborative rationality for public policy. Abingdon, Routledge.

Jackson, J. B. (1980) The necessity for ruins, and other topics. Amherst, University of Massachusetts Press.

Jacobs, J. M. \& Merriman, P. (2011) Practising architectures. Social \& Cultural Geography, 12(3), pp. 211-222. DOI: 10.1080/14649365.2011.5 65884

Jovanović Weiss, S. (2013) National, un-national. Nationalities Papers, 41(1), pp. 90-108. DOI: 10.1080/00905992.2012.748735

Karahasan, D. \& Drakulić, S. (1994) Sarajevo, exodus of a city. New York Kodansha International.

Kmezić, M., European Parliament \& Directorate-General for External Policies of the Union (2015) The Western Balkans and EU enlargement: Lessons learned, ways forward and prospects ahead: In-depth analysis. Luxembourg, Publications Office. 
Kramer, K. \& Short, J. R. (2011) Flânerie and the globalizing city. City, 15(3-4), pp. 322-342. DOI: 10.1080/13604813.2011.595100

Lopes de Souza, M. (2015) From the "right to the city" to the right to the planet: Reinterpreting our contemporary challenges for sociospatial development. City, 19(4), pp. 408-443.

DOI: $10.1080 / 13604813.2015 .1051719$

Markowitz, F. (2007) Census and sensibilities in Sarajevo. Comparative Studies in Society and History, 49(1), pp. 40-73.

DOI: $10.1017 /$ S0010417507000400

Morley, D. \& Robins, K. (1995) Spaces of identity: Global media, electronic landscapes, and cultural boundaries. London, Routledge. DOI: $10.4324 / 9780203422977$

Mrduljaš, M., Kulić, V., Arbutina, D. \& Udruženje Hrvatskih Arhitekata (eds.) (2012) Unfinished modernisations: Between utopia and pragmatism. Architecture and urban planning in the former Yugoslavia and the successor states. Zagreb, UHA/CCA.

Nohl, W. (2001) Sustainable landscape use and aesthetic perception - preliminary reflections on future landscape aesthetics. Landscape and Urban Planning, 54(1), pp. 223-237.

DOI: 10.1016/S0169-2046(01)00138-4

Olsen, B. \& Póra Pétursdóttir (eds.) (2014) Ruin memories: Materiality, aesthetics and the archaeology of the recent past. London, Routledge.

Parker, S. F. (2001) Community, social identity and the structuration of power in the contemporary European city. City, 5(2), pp. 189-202. DOI: $10.1080 / 13604810120092463$

Pendlebury, J. R., Erten, E., Larkham, P. J. \& Sonne, W. (eds.) (2015) Alternative visions of post-war reconstruction: Creating the modern townscape. London, Routledge.

Perry, V. (2003) Reading, writing and reconciliation: Educational reform in Bosnia and Herzegovina. Available at: http://www.ecmi.de/uploads/ tx_lfpubdb/working_paper_18.pdf (accessed 30 Jun. 2016).

Pilav, A. (2012) Before the war, war, after the war: Urban imageries for urban resilience. International Journal of Disaster Risk Science, 3(1), pp. 23-37. DOI: 10.1007/s13753-012-0004-4

Russo, F., Rindone, C. \& Panuccio, P. (2016) European plans for the smart city: From theories and rules to logistics test case. European Planning Studies, 24(9), pp. 1709-1726. DOI: 10.1080/09654313.2016.1182120

Schuman, M. (2004) Serbia and Montenegro. New York, Facts On File.

Schwenkel, C. (2013) Post/socialist affect: Ruination and reconstruction of the nation in urban Vietnam. Cultural Anthropology, 28(2), pp. 252277. DOI: $10.1111 /$ cuan. 12003

Sell, L. (2003) Slobodan Milosevic and the destruction of Yugoslavia. London, Duke University Press.

Simic, A. (2000) Nationalism as a folk ideology: The case of former Yugoslavia. Neighbours at war: Anthropological perspectives on Yugoslav ethnicity, culture and history, pp. 103-115. Pittsburgh, Pennsylvania State University Press.

Söderström, O., Paasche, T. \& Klauser, F. (2014) Smart cities as corporate storytelling. City, 18(3), pp. 307-320.

DOI: $10.1080 / 13604813.2014 .906716$

Sorabji, C. (2006) Managing memories in post-war Sarajevo: Individuals, bad memories, and new wars. Journal of the Royal Anthropological Institute, 12(1), pp. 1-18. DOI: 10.1111/j.1467-9655.2006.00278.x

Stead, N. (2003) The value of ruins: Allegories of destruction in Benjamin and Speer. Form/Work: An Interdisciplinary Journal of the Built Environment, 6, pp. 51-64. Available at: http://naomistead.com/ wp-content/uploads/2008/09/stead_value_of_ruins_2003.pdf (accessed 15 Sept. 2017).
Sternberg, R. (1991) The urban aesthetic in comparative perspective. Environmental, Urban and Geographic Studies, 24, pp. 70-79. Available at: http://msaag.org/wp-content/uploads/2013/04/12_Sternberg.pdf (accessed 22 Dec. 2016).

Thomas, N., Mikulan, K. \& Pavlović, D. (2006) The Yugoslav wars. Oxford, Osprey.

Thomas, R. (1998) Serbia under Milošević: Politics in the 1990s. London, C. Hurst \& Co.

Todorova, M. N. (1997) Imagining the Balkans. New York, Oxford University Press.

Udelsmann Rodrigues, C. \& Frias, S. (2016) Between the city lights and the shade of exclusion: Post-war accelerated urban transformation of Luanda, Angola. Urban Forum, 27(2), pp. 129-147. DOI: $10.1007 / \mathrm{s} 12132-015-9271-7$

Udovički, J. \& Ridgeway, J. (eds.) (2000) Burn this house: The making and unmaking of Yugoslavia (Revised and expanded). Durham, Duke University Press.

Wiig, A. (2015) IBM's smart city as techno-utopian policy mobility. City, 19(2-3), pp. 258-273. DOI: 10.1080/13604813.2015.1016275

Zucker, P. (1961) Ruins. An aesthetic hybrid. The Journal of Aesthetics and Art Criticism, 20(2), p. 119. DOI: 10.2307/427461 